\title{
Potenciais atrativos de comunidades tradicionais: turismo comunitário em Barbados, Guaraqueçaba (PR)
}

\author{
Lifestyle in the communitarian tourism based: the case of Barbados, \\ Guaraqueçaba (PR, Brazil)
}

\section{Gabriel Chagas Teodózio Prudêncio Coutinho, Carlos Alberto Cioce Sampaio, Lígia de Paula Rodrigues}

\begin{abstract}
RESUMO
A comunidade tradicional caiçara de Barbados está inserida no interior no Parque Nacional de Superagui (ParNa Superagui), Unidade de Conservação (UC) de proteção integral que não permite residência de pessoas no seu interior, problemática esta que gerou conflitos históricos com os caiçaras. Em complexo contexto de tradicionalidades e conflitos, busca-se identificar e ao mesmo tempo analisar potenciais atrativos para o turismo comunitário em Barbados por meio da percepção dos imbricamentos da cultura tradicional na perspectiva dos moradores, adotando metodologia de pesquisa-ação e grupos de foco. Obteve-se como principais resultados: praticas tradicionais são importantes para conservação dos modos de vida caiçaras, produção e conhecimento local, portanto para o turismo comunitário; existência de restrições para manutenção destes modos de sobrevivência que, por sua vez, são atrativos do turismo comunitário e; possibilidade de cogestão sobre a perspectiva do desenvolvimento e meio ambiente. O Turismo comunitário pode aproximar comunidade e ParNa Superagui por ser perspectiva comum, e, se bem planejado, pode ser atividade estratégica para amenizar processo de êxodo migratório de caiçaras para centros urbanos.
\end{abstract}

PALAVRAS-CHAVE: Turismo de Base Comunitária; Desenvolvimento; Planejamento Participativo; Comunidades Tradicionais Caiçaras.

\begin{abstract}
Barbados' traditional Caiçara community is located into the National Park of Superagui, a protected Environmental Conservation Unit where inhabitants are not allowed in its interior, it is an issue that has caused historical conflicts with the natives. In a complex context of traditionalism and conflicts, it is aimed to identify and at the same time to analyze attractive potentials for the Community Tourism in Barbados through the perception of the traditional culture's relationships, from the people's perspective, adopting the methodology of actionresearch and focus groups. It has been obtained as main results: traditional practices are important for the conservation of Caiçaras' ways of life, production and familiarity with the area, and thus, for the Community Tourism; existence of restrictions to maintain these ways of life, which are important for the Community Tourism and; the possibility of co-management through both the development and environment's perspective. The Community Tourism is able to establish links between the community and the National Park of Superagui due to their common perspective, and, if well planned, it may also be a strategic activity to reduce Caiçara people's out-migration process to urban places.
\end{abstract}

KEYWORDS: Communitarian Tourism Based; Development; Participative Planning; Traditional Caiçara Communities.

Página 972 Revista Brasileira de Ecoturismo, São Paulo, v.6, n.5, nov 20I3-jan 2014, Pp.972-989. Sociedade Brasileira de Ecoturismo. Rua Dona Ana, 138, Vila Mariana, São Paulo, SP - Brasil. E-mail: rbecotur@sbecotur.org.br; Tel. (55-II) 99196-7685 


\section{Introdução}

A inclusão social é, atualmente, um das premissas centrais nas políticas ambientais no Brasil. Com autorreconhecimento, por parte do poder público, dos limitantes na gestão para conservação ambiental, há tendência de protagonizar comunidades locais na vigilância e monitoramento destas áreas, a partir do reconhecimento das multifuncionalidades inerentes. Porém, o fomento à participação ativa dos moradores locais requer percepção de realidade complexa: perspectiva local, histórico de conflitos, êxodo rural, modos de produção, impactos socioculturais, dinâmicas sociais, dentre vários outros aspectos.

Estratégias de planejamento e gestão necessitam de base de dados confiáveis do território, sobretudo produzidas pelos próprios moradores, evitando decisões unilaterais, por meio de processos que fluam de "baixo para cima", encorajado por soluções criativas. Avançar na qualificação de técnicas que estimulem tal processo é a problemática deste artigo, com base na experiência junto a comunidade tradicional caiçara de Barbados, município de Guaraqueçaba, Paraná, Brasil

Essa comunidade foi inserida no interior no Parque Nacional de Superagui (ParNa Superagui) em 1997, porém, não foi realocada, como prevê a legislação específica de unidades de conservação (UC) de proteção integral. Seguindo política ambientalista da época, a UC proibiu realização de modos de produção tradicionais, entendendo-as como prejudiciais ao ecossistema Mata Atlântica. Tal fato gerou conflitos entre a gestão do ParNa e as comunidades locais. A atividade do turismo, atualmente, é estratégia do ParNa para o desenvolvimento das comunidades locais, o que traz novos elementos na percepção desse conflito.

A cultura caiçara possibilita oferta de vivência comunitária, atrativos do chamado turismo comunitário, e desperta interesse de demandas turísticas oriundas de centros urbanos que buscam resignificações na relação homem e natureza. As vivências são os próprios modos de vida, produção e conhecimento das comunidades locais, caracterizadas como atividades humanas de baixo impacto ambiental. Há motivações, portanto, para serem consideradas atividades permissivas, mesmo em UC de proteção integral

Em complexo contexto de tradicionalidades e conflitos, a pesquisa tem por objeitvo identificar e analisar potenciais atrativos para o turismo comunitário em Barbados, por meio da percepção dos moradores sobre cultura local. Utiliza-se metodologia participativa, com método da pesquisa-ação e grupo de foco.

O grupo de foco realizado com informantes-chaves de Barbados identificou diversidade de temáticas a respeito da cultura tradicional, o que possibilitou obter visão ampliada do contexto local, necessário para o planejamento responsável do turismo comunitário.

\section{Cultura}

Em sentido mais amplo, cultura é tudo que foi construído, adaptado ou 
modificado na natureza pelo homem. Traços culturais que caracterizam cada grupo humano são influenciados pela forma como esse grupo se apropria do ambiente natural, no qual está inserido (ALFONSO, 2003). Para Cuche (2002) existem tantas culturas distintas quanto espaços e geografias diversas no mundo, e ela é dinâmica, pois o ser humano sempre buscou e buscará adaptar-se ao seu ambiente.

Cultura é transmitida por tradições e reformulada em função do contexto histórico. Quanto mais uma sociedade consegue manter suas referências culturais, mais ela pode conservar os valores que são inerentes a ela (GOULART \& SANTOS, 1998).

Todo o conjunto de manifestações/expressões populares e modos tradicionais de apropriação do ambiente natural que diferencia uma comunidade das demais, ou seja, que the confere 'identidade', pode ser considerado como patrimônio cultural. Para Souza e Filho (1999 apud NITSCHE, 2007)

Enquanto o patrimônio natural é a garantia de sobrevivência física da humanidade, que necessita do ecossistema para viver, o patrimônio cultural é a garantia de sobrevivência social dos povos, porque é produto e testemunho de sua vida. (p. 20)

Turismo utiliza assim o patrimônio cultural para conformação de produtos turísticos (GANDARA et al., 2005).

\section{Turismo comunitário}

Nas relações estabelecidas por meio do turismo, dar-se-á transferência de elementos culturais que afetam invariavelmente, em maior ou menor medida, turista e autóctone; este intercâmbio poderá ser benéfico ou prejudicial, dependendo em parte do planejamento turístico, mas também do grau de identificação étnica dos implicados. Segundo Alfonso (2003), a melhor forma para que turistas conheçam e respeitem patrimônio do lugar que visitam é que, de alguma forma, sintam-se identificados; turistas devem ser observadores ativos, manifestando reações quanto ao ambiente e pessoas. É necessário despertar processo cognitivo e sensibilização quanto ao turismo, para ponderar impactos que a atividade pode gerar.

Os modos de vida, produção e conhecimento de comunidades tradicionais são cada vez mais recorrentes como atrativos do turismo, diante da expectativa que se valorize cada vez mais a cultura. Porém, essas comunidades com tradições enraizadas sofrem pressões exógenas que ameaçam seus meios de sobrevivência. Turismo comunitário surge como alternativa de garantir a viabilidade desses modos de vida, produção e conhecimento.

Para Coriolano e Lima (2003), turismo comunitário pode ser definido como

aquele (...) desenvolvido pelos próprios moradores de um lugar, que passaram a ser os articuladores e os construtores da cadeia produtiva, onde a renda e o lucro ficam na comunidade e contribuem para a melhoria da qualidade de vida (p. 41). 
Solidariedade é elemento principal que define o sentido de comunidade (CORIOLANO et al. 2009). Como minorias sociais em mundo de relações globalizadas, o sentido de comunidade está exposto a riscos associados ao posicionamento desigual de seus membros em relação ao meio social, perceptível no acesso precário a serviços básicos, como saúde e educação. Porém, o turismo tem auxiliado comunidades, ao passo que estas tomam consciência das potencialidades que possui seus ativos patrimoniais: recursos culturais, naturais, físicos e humanos (MALDONADO, 2005).

Como proposta de empoderamento ${ }^{1}$ dessas minorias sociais, o turismo comunitário procura promover o contato do visitante com o sentido comunitário, para gerar relações de convivencialidade ${ }^{2}$.

É por meio das chamadas vivências comunitárias que característica da convivencialidade se expressa no turismo comunitário. As vivências são os modos de vida da comunidade geralmente transmitidos de geração em geração, como modos de produção artesanais e atividades extrativistas, agrícolas e de pesca, formatadas para permitir a participação ativa dos turistas. Por reproduzirem modos de produção tradicionais, fortalecem aspectos histórico-culturais, organização social e governança local, além de possibilitarem a geração trabalho e renda quando associadas a serviços turísticos. Nesse sentido, as vivências são bases para formatação de experiências de turismo comunitário (SAMPAIO; ZAMIGNAM, 2012).

Hospitalidade também é conceito arraigado nas vivências de turismo comunitário. Para Kant (apud PERES, 2007), hospitalidade se representa por meio do respeito no sentido de ver ao próximo como semelhança de si próprio, e amor como prática de benignidade, benevolência.

\section{Comunidades tradicionais caiçaras}

Comunidades tradicionais, para Diegues (1996, p. 79), estão relacionadas a tipo de organização econômica e social em que produtores estão envolvidos em atividades de pequena escala, como extrativismo, agricultura e artesanato e são conhecedores dos recursos e serviços naturais, seus ciclos biológicos e hábitos alimentares. Almeida (2008) interpreta que a categorização "comunidades tradicionais" designa atores sociais mobilizados, conscientes de sua identidade. Nessa perspectiva, o significado de "tradicional" se apresenta dinâmico e como fato presente, rompendo com a visão essencialista, que condiciona "tradição" a fatores históricos ou baseados na ancestralidade (ALMEIDA, 2008; VIANNA, 2008).

Textos legais, como decreto 60.40/07 (BRASIL, 2007) e Convenção 169 da Organização Internacional do Trabalho (OIT, 2011), abordam a temática sugerindo a autoconsciência ou autodenominação como critério para se identificar comunidades que são tradicionais, e garantem a tais comunidades acesso aos recursos naturais tradicionalmente utilizados.

Comunidades caiçaras são, tradicionalmente, extrativistas, pesqueiras e agrícolas, habitantes da região litorânea do Rio de Janeiro até o litoral paranaense, 
entre a Floresta Atlântica e o mar, em estuários, mangues, restingas e lagunas. Conformadas desde primeiros momentos da colonização europeia no Brasil, essas comunidades passaram por vários períodos e ciclos, apogeus e decadências. Tal dinâmica é própria da cultura caiçara (WILLEMS, 1952 apud DIEGUES, 2004).

As festas e rituais caiçaras mais importantes são, de maneira geral, associados às práticas de sociabilidade existentes nas atividades agrícolas (DIEGUES, 2006). Como não havia prática do uso de unidade monetária nas comunidades, o beneficiado do mutirão ${ }^{3}$ se obrigava realizar festa como retribuição àqueles que trabalharam. Neste contexto surgiu fandango ${ }^{4}$ como manifestação cultural.

O conhecimento do meio pelo caiçara refere-se, principalmente, a formas de cultivo da terra (técnica de coivara); proibições e usos de animais e plantas; classificação da natureza (etnotaxonomia); e uso de tecnologias apropriadas (BEGOSSI, 1995 apud ADAMS, 2000b). Para Adams (2000b), essas comunidades possuem técnicas de manejo que podem contribuir na manutenção do ecossistema da mata atlântica, como possivelmente ocorre no caso da agricultura itinerante.

Segundo Adams (2000a), as populações caiçaras eram, primordialmente, constituídas por lavradores-pescadores. Porém, em meados do século $X X$, com a introdução de técnicas e instrumentos de pesca e do barco a motor, voltaram-se cada vez mais à pesca, diminuindo e até extinguindo as lavouras, pois a atividade elevou a renda local, propiciando acesso direto aos produtos antes oriundos do plantio. Diegues (2004) aponta que, a partir da década de 1960, contingente cada vez maior de caiçaras passa abandonar seu território ancestral e migrar para áreas suburbanas, exercendo atividades distintas das tradicionais, como subempregos. Abandono dos caiçaras de suas terras se deve, também, à expropriação realizada pela especulação imobiliária, urbanização e transformação do território ancestral em áreas de unidades de conservação (DIEGUES, 2004).

\section{Comunidade de Barbados}

O Litoral Norte do Paraná, Brasil, possui algumas das cidades mais antigas do estado e com destinos turísticos consolidados, como llha do Mel, Paranaguá e Morretes (LITORAL DO PARANÁ, 2008). Guaraqueçaba possui aspectos de notável relevância ambiental no contexto brasileiro, especialmente por apresentar considerável quantidade de Unidades de Conservação (KASSEBOEHMER, 2007), porém possui o sétimo pior IDH no Estado do Paraná (RODRIGUES, 2005).

ParNa Superagui se localiza no município de Guaraqueçaba. O decreto de criação da UC, em 1989, não incluía em seus limites nenhuma comunidade tradicional local. No entanto, com a ampliação do Parque em 1997, sete delas tiveram suas vilas e territórios tradicionais inseridos no interior da UC, dentre elas encontra-se a comunidade de Barbados.

Guadalupe Vivekananda (2001), vice chefe do ParNa Superagui, constatou 
que comunidades no interior e entorno da unidade estão passando por processo de descaracterização sociocultural, gerado por maior acesso aos produtos industrializados e à mudança de hábitos, que provocou a extinção de atividades extrativistas relacionadas à vegetação e aos animais silvestres. Sobre a atividade agrícola, a autora aduz que não é possível relacionar a queda desta à criação da unidade, e justifica que, segundo as comunidades, isso aconteceu quinze anos antes da criação do parque ${ }^{5}$. Porém, Bazzo (2010) aponta que, do ponto de vista do nativo, a criação do ParNa Superagui concretizou de vez a interrupção das lavouras ${ }^{6}$.

Bresolin (2009), chefe do ParNa Superagui, em entrevista, expôs sua visão sobre as comunidades situadas no interior e entorno da unidade:

Os comunitários possuem grande resistência e descrédito em relação aos órgãos ambientais e às ONGs, muito em função da ausência de políticas públicas de saúde, educação e plano de manejo. Mas também originados por uma dificuldade histórica de associativismo e da repetição dos velhos discursos, verdadeiros "mitos" contra as unidades de conservação. Um dos maiores desafios será reverter a imagem negativa do parque junto aos locais, e isso só será possível com o incremento de um turismo responsável, com uma melhoria da gestão do recurso pesqueiro e da importante ferramenta estadual do ICMS Ecológico (BRESOLIN, 2009, s/p).

O chefe da unidade transparece percepção histórica pessoal sobre a relação unidade-comunidade, e sua perspectiva para o desenvolvimento da região, que envolve o protagonismo de um "turismo responsável".

A comunidade de Barbados situa-se na Ilha de Superagui, na margem Leste da baía de Pinheiros, dentro dos limites do ParNa Superagui, município de Guaraqueçaba. Possui sessenta e nove pessoas, dezenove famílias, com acesso somente a barco, com modo de produção predominantemente voltado à pesca. Existe Associação de Moradores de Barbados que funciona à quinze anos. Há escola municipal, com aulas de primeira a quarta série, igreja católica e dois engenhos artesanais de farinha de mandioca (CULTIMAR, 2008). No início de 2013, foram instaladas placas de energia solar e entregues geladeiras novas e boilers a energia solar para aquecimento da água do banho, pelo órgão distribuidor de energia no Paraná.

É comunidade significativa por ser uma das mais antigas da região. Sua colonização foi por europeus, na primeira metade do século XIX, principalmente por franceses e suíços. Um deles foi Willian Michaud. Chegou em Superagui em 1852 e permaneceu até sua morte, em 1902. Casou-se com nativa, teve vários filhos, e é conhecido devido às pinturas que retratam modo de vida da época e natureza do lugar (LICHTSTEINER, 2008). Suas obras encontram-se no Museu Oscar Niemeyer (MON), em Curitiba e no Museu de Vevey, na Suíça, o que confere a essa comunidade contexto histórico diferenciado e relevante ao Paraná.

Sua geografia combina encostas de montanhas com pequena várzea, onde 
estão localizadas casas construídas próximas a grandes pedras, o que não permite aumento do número de pessoas da comunidade. Há igreja católica e dois engenhos artesanais de farinha de mandioca (CULTIMAR, 2008).

A pesca é a mais importante atividade da comunidade. Há também extração de caranguejo e ostras. Atividade agrícola é influenciada por cultura indígena e europeia. Porém, cabe destacar que são poucas roças na região, o que também se deve ao fato do território ter sido delimitado como área do Parque Nacional de Superagui, o qual proíbe qualquer forma de extração de fauna e flora da Mata Atlântica.

Turismo acontece principalmente no verão, quando muitos turistas que estão na Barra de Superagui, Ilha das Peças e Guaraqueçaba vão conhecer a revoada dos papagaios. Visitação ocorre ocasionalmente quando embarcações atracam em Barbados para pessoas poderem comer no restaurante e comprar artesanato no espaço comunitário.

\section{Metodologia}

As técnicas metodológicas propostas foram os passos iniciais no processo de planejamento do turismo comunitário em Barbados, e utilizou como embasamento prévio o conhecimento adquirido por meio da observação participante.

O processo de planejamento promove um espaço de reflexão democrática e conscientização dos problemas locais e das possíveis soluções para estes problemas (SAMPAIO et al., 2010). Para que represente efetivamente as ambições da comunidade de um dado destino, há necessidade de que esta esteja envolvida de forma ativa, apropriando-se do conceito de participação.

Demo (1993, p. 37) expõe que a "participação nunca é completa e ideal, mas sempre um processo. (...) Não é dádiva, se for ela é tutelada e controlada. Não é concessão. É espontânea, é conquistada". Paulo Freire (1997) afirma que as populações locais são capazes e devem conduzir suas próprias pesquisas e análises da realidade local. Os problemas a serem solucionados devem ser demandas locais, e não por meio de processo de "cima para baixo" ( DEMO, 1993).

A abordagem utilizada foi a pesquisa-ação. Segundo Seixas (2005), nela há empoderamento de atores sociais comunitários, valorizando uso do conhecimento local de maneira a atuarem como protagonistas na identificação ou refinamento tanto de problemas de pesquisa bem como nas alternativas de solução desses.

Para obtenção da participação local no processo de planejamento do turismo comunitário, utilizou-se técnica qualitativa da pesquisa-ação e grupo de foco. É método de coleta de dados que consiste na realização de entrevistas em grupo, conduzidas por moderador, tendo como objetivo a discussão de um tópico 
específico (MATTAR apud VERGARA, 2005). A técnica foi definida para que houvesse maior diálogo e aprofundamento em temas específicos. $O$ aprofundamento e maior diálogo possivelmente não seriam alcançados com técnicas como reunião comunitária ou entrevistas individuais.

O grupo de foco foi realizado no dia 01/11/2010. Em reunião comunitária realizada anteriormente, contextualizou-se a pesquisa e seis pessoas se mostraram interessadas a participarem do grupo de foco. Os participantes podem ser considerados informantes-chave ${ }^{7}$ : Participantes 1 e 2 são lideranças políticas de Barbados; Participante 3 possui olhar para a educação; Participante 4 é conhecedora de terapias alternativas por meio de ervas e rezas; Participante 5 é socioempreendedor comunitário; e Participante 6 é membro ancestral da comunidade, utilizando-se de oralidade e histórias, com olhar do passado e presente.

Inicialmente, foram discutidos temas: cultura e patrimônio cultural, cultura caiçara e turismo comunitário. Com essa base, o grupo definiu os temas da cultura local importantes para serem aprofundados: pesca; agricultura; artesanato; terapias alternativas, parto natural e oralidade; gastronomia; festas populares; cozinha comunitária e Willian Michaud; e hospitalidade/convivencialidade. Os dados analisados em cada um dos temas são apresentados a seguir. Posteriormente, com base nos dados analisados, apresenta-se potencial de atratividade do turismo comunitário em Barbados.

\section{Apresentação e análise dos dados coletados}

\section{Pesca}

Pesca na comunidade, segundo Participante 1, é bem cultural tradicional por se tratar de atividade artesanal. Para ele, métodos tradicionais de pesca, como engodo $^{8}$, quando tinha fartura e eram permitidos, davam condições para que atividades paralelas, como trabalho na roça, fossem possíveis, já que a pesca demandava menos tempo. Expõe que atualmente a pesca é atividade principal, mas está sendo transformada desde a instalação na região do Parque Nacional, no qual órgãos ambientais vêm intensificando a fiscalização quanto à regulação das atividades econômicas, assim como proíbe a agricultura na comunidade. Para ele, também há desinteresse da geração mais jovem em continuar a tradição do trabalho na roça. Há receio, comenta o Participante, de ter a pesca como única atividade econômica, pois recursos pesqueiros são esgotáveis. O que sugere é regulação menos proibitiva no manejo da mata, para tornar a atividade agrícola possível.

Para a comunidade, a área protegida ParNa Superagui é uma das responsáveis pela inibição da agricultura, não só pela proibição explicita de não realizar as roças, como também na proibição de técnicas de pesca menos laboriosas, que permitiam conciliar tempo para o plantio. Torna-se importante aprofundar estudos sobre tais técnicas de pesca, entendendo seus impactos em cenário atual de aumento da extração e queda no volume de peixes nas baías da região. 
Sobre atividades vinculadas à pesca, como a produção de canoas, Participante 3 relata que deve haver sinergias na comunidade para enfrentamento das dificuldades para que não haja sobrecarga de trabalho por parte das lideranças locais, assim não se corre risco de desarticulações comunitárias. Se oculta produção artesanal de canoa para que não haja denúncias, por causa da proibição do Parque. Produção ocorre, pois é meio de mobilidade para que ocorra pesca, único meio de sobrevivência permitido. Recorda que cuia, extraída da árvore chamada "porongo", para retirar água do barco foi substituída pela garrafa tipo pet.

Os receios de denúncias entre os próprios moradores geram desarticulação e perda do sentido de comunidade, consequência do medo gerado pelos órgãos ambientais. A falta de coesão local inibe a defesa do território tradicional contra as leis ambientais restritivas, o que pode sobrecarregar as lideranças, como exposto pelo Participante 2. Esse cenário gera ciclo constante de desarticulação social, que pode causar, por exemplo, êxodo rural.

\section{Agricultura}

Participante 1 sugere que cultura do plantio pode ser preservada, a partir de estímulo como sementes de arroz. Antigamente, tudo o que se comia era originado dos próprios cultivos, o que não gerava resíduos. Trabalho da roça prescindia prática do mutirão ou "sapo", incentivando solidariedade comunitária. Depois de termino do trabalho, o proprietário oferecia fandango, prática cultural que estabelecia e fortalecia vínculos sociais, como o namoro. Participante 6 afirma que não há ninguém vivo na Vila que toque fandango. Participante 3 afirma que embora ainda haja engenho de farinha na Vila, não se utiliza mais, pois não se pode plantar por conta da instalação do Parque.

Observa-se que a roça estimula a solidariedade e é atividade protagonista em rede de interações socioculturais caiçaras, como exposto por Diegues (2006). Segundo o Participante 1, havia quadro de descaracterização da tradição do plantio, sendo necessário incentivos conjuntos para o fomento, entendendo a atividade como modo produção que, aparte benefícios para a cultura local, pode contribuir na manutenção do ecossistema da mata atlântica, como sugere Adams (2000b). Como comentou Participante 1, a inibição da agricultura aumentou o volume de resíduos na comunidade, principalmente embalagens de alimentos adquiridos nos centros urbanos. Como não há coleta de lixo em Barbados por parte do poder público, são queimados e enterrados nas encostas da Mata Atlântica, o que gera impactos ambientais e possíveis problemas de saúde nos moradores. É estratégico, portanto, o fomento à atividade agrícola por parte dos órgãos de desenvolvimento na região, para melhoria sociocultural e ambiental.

\section{Artesanato}

Participante 2 afirma que tipos de artesanatos que eram produzidos, atualmente não são mais, como artesanato de barro. Há casos ocultos de produção, 
como balaio, peneira, viveiro para camarão e vassoura, pois são produzidos a partir do cipó imbé, matéria-prima proibida de extração. Exemplifica que mesmo orquídea, para enfeitar jardim, não pode ser mais extraída da mata. Alega que se depender da legislação do Parque, não se faz nada. Daí a importância de se associar comunitariamente para poder negociar com os gestores. Feitio de artesanato mais comum é de técnica forânea, como tapetes de retalhos de plástico e camisas serigrafadas de xilogravuras vendidas para turistas.

Técnicas tradicionais de produção de artesanatos, como exposto pelo Participante 2, estão ou já se perderam, e muito se deve à inclusão de tecnologias, como no caso da não-utilização de panelas de barro, provavelmente devido ao acesso a panelas de metal, ou da substituição da cuia do "porongo" pela garrafa pet. Porém, comunidade deseja manter a prática de artesanatos tradicionais, mesmo com a inserção de técnicas forâneas voltadas para o turismo.

\section{Terapias alternativas, parto natural e oralidade}

Participante 6 relata que muitos moradores foram tratados, quando sentiam mal estar, com ervas medicinais. Gostaria que esta prática fosse transmitida para demais gerações. Tal prática foi aprendida com seu próprio pai. Recorda que sofreu pressão, principalmente da religião na qual escolheu fazer parte, para não se utilizar mais da manipulação de ervas e que era chamada de feiticeira. No entanto, sentimento de utilizar terapias alternativas curar a faz continuar com tal prática. Participante 2 recorda de agente comunitária tradicional, que era parteira da região. Participante 6 relata que sempre gostou de dialogar com pessoas sobre a comunidade, de como era antes e tratar das dificuldades atuais.

Práticas alternativas com usos de ervas medicinais e da oralidade, geralmente vinculadas aos mais idosos, ainda estão presentes. Tais práticas sofrem impactos e influências diretas do recente fenômeno de certas religiosidades institucionalizadas nessas comunidades. Porém, como exposto pelo Participante 6 , tal fenômeno ainda não foi capaz de ruir com algumas práticas tradicionais caiçaras, no caso de Barbados.

\section{Gastronomia}

Participante 3 enumera pratos típicos da região, como peixe seco com banana, caranguejo, ostra assada, camarão abafado, biju de manipuva, licor de gengibre, cravo, canela e anis, e broinha de goma de mandioca. Relata que alguns pratos não são mais preparados com frequência, porque há ingredientes que não se podem mais ser colhidos por seu plantio estar proibido e que existe menos momentos de confraternização da comunidade, como havia antigamente mais mutirões. Licor praticamente não se produz mais, embora seja lembrado pelo seu bom paladar, pois se era oferecido a quem participava do mutirão.

Há perdas na gastronomia local como consequência da queda no plantio, 
tanto devido à falta de ingredientes antes agricultáveis, quanto à falta de momentos de trocas solidárias, caso dos mutirões.

\section{Festas populares}

Participante 3 relata que Dezembro é o mês da tradicional Festa de Nossa Senhora da Conceição, padroeira da vila, no qual predomina festejo de batizados, casamentos e primeira comunhão. Há festas que não se comemoram mais e que deixam saudades, como festa Junina. Durante Carnaval, eram produzidas máscaras de barro pintadas. Embora haja disposição do Participante e das crianças da escola para trabalharem na preparação de festas, não há ninguém para ajudá-lo. E considera necessário mobilizar a comunidade para resgatar tais festejos.

\section{Cozinha comunitária e Willian Michaud}

Participante 5 afirma que muitos moradores da comunidade possuem sobrenome Michaud. Participante 3 realça a importância de tal sobrenome, considerando-o como patrimônio cultural imaterial. Há ainda presença de bem material que são as ruínas de sua antiga casa. Participante 2 recorda de trilhas na mata que conduzem a outras ruínas e que poderiam ser visitadas. Participante 3 recorda que a cozinha comunitária é nominada Willian Michaud, onde existem fotografias de telas do protagonista e artesanatos para venda.

Observa-se que Barbados orgulha-se da figura de Willian Michaud, o que gera autoestima local e amplia senso de pertencimento no território tradicional, povoado de histórias da época, mitos e ruínas históricas.

\section{Hospitalidade/Convivencialidade}

Todos Participantes destacam predisposição de receber visitantes, principalmente quando estes veem para conhecer seus modos de vida. Participante 2 destaca que todo mundo sempre tem algo a ensinar e a apreender. Participante 1 afirma que quando se recepciona visitantes, agrega-se ainda renda às famílias.

A hospitalidade é característica das comunidades caiçaras. Observa-se que possuem predisposição para modalidade de turismo motivada por trocas culturais, como turismo comunitário, como também percebem a atividade como geradora de renda.

\section{Potenciais atrativos para o turismo comunitário}

Com base na análise dos dados apresentados, visualizaram-se potenciais atrativos para o turismo comunitário. Modos de produção relacionados à pesca artesanal e extração de ostras podem ser considerados dentro da perspectiva do turismo comunitário, pois fortalecem tais modos de produção ao serem valorizados pelos visitantes. 
A agricultura, como observado, é protagonista nas interações socioculturais caiçaras. O turismo pode ser instrumento de defesa de tal prática tradicional perante os gestores do ParNa Superagui, que desejam fomentar turismo responsável na região (BRESOLIN, 2009). A agricultura oferece a vivência da extração da mandioca e, principalmente, da fabricação da farinha artesanal, tendo forte apelo para o turismo. Observa-se que para turismo comunitário em Barbados é importante a legalização da prática do plantio. Dessa forma, há imbricamento entre atividades agrícolas e turismo nessa comunidade.

Turismo comunitário pode fomentar mutirões de trabalho entre visitantes e visitados, entendendo tal prática como fortalecedora da solidariedade no local. A atividade tem potencial para resgatar outros elementos da cultura local, como gastronomia típica ou mesmo o fandango, no momento da complexa interação com os turistas.

Por meio da oralidade, modos de vida e histórias tradicionais se transformam em atrativos aos turistas. Relato do próprio uso restritivo de recursos naturais aos visitantes pode gerar sensibilização sinérgica na opinião popular quanto à situação singular que vivem comunidades locais, pressionadas por Unidade de Conservação de uso restritivo. Vivências para ensinamento de terapias alternativas de uso de ervas medicinais possui forte apelo para público do turismo comunitário. Tal atividade tem ainda potencial para resgatar festividades locais, como São João.

Há potencial também para o guiamento de turistas para conhecer ruínas históricas e apresentação de elementos da fauna e flora local. Na atividade do turismo comunitário, é importante que guias sejam locais, o que incrementa a geração de trabalho e renda.

A prática tradicional da fabricação de artesanato pode ser vivência comunitária, ensinando os visitantes a produzirem seus próprios artesanatos, estimulando processo de troca de saberes. Dessa forma, a geração de trabalho e renda é obtida pelo serviço prestado, não somente pela eventual venda de artefatos, o que pode amenizar impactos ambientais que seriam gerados pela extração massiva de cipós. A transmissão da prática tradicional gera autoestima local. O turismo comunitário elimina ou estimula a figura do atravessador espúrio, ao aproximar produtor do consumidor final, gerando trocas e ganhos justos. A utilização de outros insumos como alternativas para produção de artesanatos, como reciclar saco plástico para fabricar tapetes, demonstra dinamicidade e capacidade da cultura comunitária de se adaptar às limitações impostas.

Hospitalidade e convivencialidade, por fim, é base para que experiência turística comunitária se realize. Bem receber, bem querer o outro é atrativo diante de crise civilizatória que se vive. 


\section{Conclusões}

O instrumento metodológico utilizado estimulou participação pró-ativa do grupo, na exposição de aspectos de sua própria cultura tradicional. Os dados alcançados possuem profundidade, pois entrelaçam o processo de construção da identidade local com pressões e conflitos recentes, permitindo ampliar a percepção sobre como a atividade do turismo pode se inserir no contexto. Devem balizar, portanto, o planejamento do turismo no local, tanto na estruturação, qualificação, promoção e, talvez principalmente, no monitoramento da atividade. Aspectos da cultura tradicional são elementos em constante transformação e, entendendo o turismo como gerador de impactos negativos inevitáveis, importa conhecer e monitorar a cultura tradicional, para que 0 fenômeno não descaracterize as bases que o fazem existir.

É provável que simples replicação de modelos metodológicos de planejamento, pré-estabelecidos, não desvendariam aspectos anteriores e essenciais na construção do turismo comunitário. Esse fenômeno consolida-se na diversidade: de modos de vida, produção e conhecimento, de atores locais, fatores motivacionais dos visitantes, possibilidades de intercâmbio e atrativos no local, redes de distribuição e promoção, e disciplinas científicas para seu desenvolvimento e compreensão. Nesses aspectos, turismo comunitário ancora-se na perspectiva de desenvolvimento à escala humana, proposto por Max-neef (2013), para construção de outra sociedade, embasada na diversidade, e não na hegemonia de único modelo socioeconômico.

Como principais conclusões, observou-se que: receio gerado por leis ambientais restritivas gera desarticulação e perda do sentido de comunidade em Barbados; ParNa Superagui é um dos responsáveis pela inibição da agricultura, na visão local; a prática da roça estimula solidariedade e é atividade protagonista em rede de interações socioculturais caiçaras, o que pode contribuir na manutenção do ecossistema da Mata Atlântica, e sua inibição aumentou volume de resíduos, que gera impactos ambientais e possíveis problemas de saúde no local; há perdas na gastronomia tradicional como consequência da queda na atividade agrícola; práticas de terapias alternativas tradicionais, usos de ervas medicinais e oralidade estão presentes em Barbados; hospitalidade é característica da cultura caiçara; há predisposição local para turismo comunitário; percebem a atividade do turismo como geradora de trabalho e renda.

Observou-se que a cultura tradicional da comunidade de Barbados sofre pressões decorrentes de: leis ambientais, certas religiões institucionalizadas, globalização e novas tecnologias, turismo e falta de interesse do poder público no desenvolvimento local. A cultura poderá ser fortalecida com mutirões, agricultura, práticas tradicionais, inclusão social e digital responsável e turismo comunitário.

São vivências potenciais do turismo comunitário em Barbados: pesca, extração de ostra, cipó e flora, colheita da mandioca, fabricação de farinha 
artesanal, mutirões de trabalho coletivo para construção a partir de necessidades locais, fandango, culinária típica, oralidade, ensino das ervas medicinais, trilhas para as ruínas históricas, saberes locais sobre a fauna e flora, fabricação de artesanato tradicional, hospitalidade na hospedagem nas casas. Vivências possíveis relatadas pelos informantes-chave constituem prospecção de arranjo socioprodutivo de base territorial, no qual relações são compreendidas como encadeamentos verticais, do produtor ao distribuidor, e horizontais, entre parcerias institucionais e prestadores de serviço.

O turismo comunitário em Barbados tem potencial para aproximar visão local e dos gestores do ParNa Superagui, por ser instrumento de desenvolvimento almejado por ambos. Porém, práticas tradicionais hoje proibitivas necessitam ser estimuladas, pois são importantes na construção sociocultural local, portanto bases estruturantes do turismo comunitário, como a prática agrícola, artesanatos com cipó e modalidades de pesca. Como observado, não basta permitir, mas ações de fomento a tais práticas devem ser prioridades em perspectivas desenvolvimentistas nas comunidades tradicionais. Dessa forma, moradores estarão preparados para enfrentar a possível inclusão global digital, se assim ocorrer, e o turismo, sem esquecerem a identidade, tradição e valores caiçaras.

Turismo se bem planejado pode ser atividade estratégica para amenizar processo de êxodo migratório de caiçaras para centros urbanos. É instrumento de revalorização cultural, associativismo comunitário e geração de trabalho e renda. Cooperação tem funcionalidade de ligação dos elementos essenciais para que a atividade aconteça. Mesmo porque dificuldades, bem como a superação dessas, são características do turismo comunitário.

\section{Referências bibliográficas}

ADAMS, C. As populações caiçaras e o mito do bom selvagem. Revista de Antropologia, v. 43, no 1, p. 145-182, 2000a.

ADAMS, C. As roças e o manejo da Mata Atlântica pelos caiçaras. Interciência, v. 25, no 3, p. 143-150, 2000b.

ALFONSO, M.J.P. El patrimônio cultural como opción turística. Horizontes Antropológicos. Porto Alegre, ano 9, n.20, p. 97-115, outubro de 2003.

ALMEIDA, A.W.B. Terras de quilombo, terras indígenas, "babaçuais livres", "castanhais do povo", faxinais e fundos de pasto Manaus: PGSCA-UFAM, 2008.

BAZZO, J. Mato que vira mar, mar que vira mato. Dissertação de Mestrado em Antropologia Social, Departamento de Antropologia, Setor de Ciências Humanas, Letras e Artes. UFPR. Curitiba, 2010. 
BRASIL. Decreto n. 6.040/07. Institui a PNPCT - Política Nacional de Desenvolvimento Sustentável dos Povos e Comunidades Tradicionais. Diário Oficial, Brasília-DF, 2007. Disponível em: http://www.mds.gov.br/backup/ institucional/secretarias/secretaria-de-articulacao-institucional-e-parcerias/ arq uivo -saip/povos-e-comunidades-tradicionais-1/decreto 60402007 pnpct .pdf/ view. Acesso: 18/09/2012.

BRESOLIM, M. Rede Nacional Pró-Unidades de Conservação. Parque Nacional de Superagui. Entrevista. 2009. Disponível em: <http://www.redeprouc.org.br/ parquesnacionais/post.asp?codigo=178 $>$. Acesso em: 29/09/2012.

CASCUDO, L.C. Dicionário do folclore brasileiro. SP: Global, 2001.

COLE, S. Beyond authenticity and commodification. Annals of Tourism Research, v. 34, n. 4, p. 943-960, 2007.

CORIOLANO, L. N. et al. Arranjos produtivos locais do turismo comunitárioFortaleza: UECE, 2009.

CORIOLANO, L.N.; LIMA, A.C.G. A Contribuição do Turismo no desenvolvimento Local. In: CORIOLANO, L.N. Turismo: Gestão da Cadeia Produtiva. Fortaleza: Edições Demócrito Rocha, 2008.

CUCHE, D. A noção de cultura nas ciências sociais. 2 ed. Bauru: EDUSC, 2002.

CULTIMAR. Recursos naturais na vida caiçara. Grupo Integrado de Aquicultura e Estudos Ambientais- UFPR. Curitiba: 2008.

DEMO, P. Participação é conquista: noções e política social participativa. $2^{\mathrm{a}}$ ed. São Paulo: Cortez, 1993.

DIEGUES, A.C.S. O mito da natureza intocada. SP: Hucitec, 1996.

DIEGUES, A.C.S. A mudança como modelo cultural: o caso da cultura caiçara e a urbanização. In: DIEGUES, A.C.S. (org.). Enciclopédia caiçara, v.1. São Paulo: HUCITEC-NAPAUB-CEC/USP, 2004.

DIEGUES, A.C.S. Cultura e meio-ambiente na região estuarina de lguapeCananéia- Paranaguá. In: PIMENTEL, Alexandre et al. (org.) Museu vivo do fandango. Rio de Janeiro: Associação Cultural Caburé, 2006.

FREIRE, P. Pedagogia da Autonomia: Saberes Necessários à Prática Pedagógica. 3를 ed. Rio de Janeiro: Paz e Terra, 1997.

GANDARA, J.M. et al. Viabilizando a relação entre cultura e o turismo: diretrizes para o estabelecimento de políticas integradas entre os dois setores. Turismo, Visão e Ação, vol.8, n.1, p. 129-140. Jan/abr. 2006.

GOULARD, M.; SANTOS, R.I.C. Uma abordagem histórico-cultural do turismo. Turismo, Visão e Ação. v.1, n. 1, p. 19-29, janeiro de 1998. 
HENRÍQUEZ, C; MANSUR, C; DIAS, A. Diálogos participativos em desenvolvimento sustentável. In: SAMPAIO, C.A.C.; HENRÍQUEZ, C.; MANSUR, C (org.). Turismo comunitário, solidário e sustentável. Blumenau: EDIFURB, 2011.

ILLICH, I. A convivencialidade. Lisboa: Europa-América, 1976.

KASSEBOEHMER, A, L. Restrições e impactos da legislação ambiental aplicada no município de Guaraqueçaba-PR. Dissertação de Mestrado em Engenharia Florestal. UFPR. Curitiba, 2007.

LICHTSTEINER, N. Memória e narrativa através das cartas de William Michaud (18481902). Trabalho de Conclusão de Curso em História. Universidade Tuiuti do Paraná, 2008.

LITORAL DO PARANÁ. Plano de desenvolvimento do turismo regional 2008-2011. Curitiba: Sebrae-PR, 2008.

MALDONADO, C. Pautas metodológicas para el análisis de experiencias de turismo comunitario. OIT. Genebra, 2005.

MAX-NEEF, M. Desenvolvimento à Escala Humana: concepção, aplicação e reflexos posteriores. Blumenau: EDIFURB, 2012.

NITSCHE, L.B. Representações geográficas e turismo: um estudo interdisciplinar. Salvador: EDUFBA, 2007.

OIT- Organização Internacional do Trabalho. Convenção $n^{\circ} 169 / 89$ sobre povos indígenas e tribais e resolução referente à ação da OIT. Brasília: OIT, 2011. Disponível: http://www.oitbrasil.org.br/sites/default/files/topic/ international_labour_standards/pub/convencao\%20169_2011_292.pdf. Acesso em: 19/09/2012.

PEREZ, D.O. Os significados dos conceitos de hospitalidade em Kant e a problemática dos estrangeiros. Konvergencias: Filosofia y culturas em diálogo. Año IV, n. 15, 2007. Disponível em: <http://www.konvergencias.net/danieloperez132.pdf> Acesso em 8/5/2009.

RODRIGUES, A.S.(Org.). As Condicionantes da Sustentabilidade Agrícola em uma Área de Proteção Ambiental: a APA de Guaraqueçaba. Curitiba: IAPAR, 2005.

SAMPAIO, C.A.C.; FERNANDES, V.; PHILIPPI JR, A. Planejamento e gestão de turismo sustentável: metodologias PEC \& SiGOS. In: RUSCHMANN, D.V.M.; PHILIPPI JR, A. Gestão ambiental e sustentabilidade no turismo. Barueri: Manole, 2010.

SAMPAIO, C.A.C.; LESAMA, M.F.; ARAÚJO, J.R.; MENDEZ, E.O. Perspectiva do Turismo Comunitário, Solidário e Sustentável. In: SAMPAIO, C.A.C.; HENRIQUEZ, C.; MANSUR, C (org.). Turismo comunitário, solidário e sustentável. Blumenau: EDIFURB, 2011.

SAMPAIO, C.A.C., LESAMA, M.F., ARAÚJO, J.R. Arranjos socioprodutivos e políticos de base comunitária, solidária e sustentável. In: PHILIPPI JR. A., SAMPAIO, C.A.C., FERNANDES, V. Gestão de natureza pública e sustentabilidade. Barueri: Manole, 2012. 
Coutinho, G.C.T.P.; Sampaio, C.A.C.; Rodrigues, L.P.

SAMPAIO, C.A.C.; ZAMIGNAN, G. Estudo da demanda turística. CULTUR, v. 6, n.1, 2012.

SEIXAS, C.S. Abordagens e Técnicas de Pesquisa Participativa em Gestão de Recursos Naturais. In: VIEIRA, P. H. F.; BERKES, F. e SEIXAS, C. S (Org.). Gestão Integrada e Participativa de Recursos Naturais: conceitos, métodos e experiências. Florianópolis: Secco/APED, 2005.

VERGARA, S.C. Métodos de pesquisa em administração. São Paulo: Atlas, 2005. VIANNA, L. P. (Org.). De invisíveis a protagonistas. SP: Annablume; Fapesp, 2008.

VIVEKANANDA, G. Parque Nacional do Superagui. Dissertação (Mestrado em Engenharia Florestal) - Setor de Ciências Agrárias, UFPR. Curitiba, 2001.

\section{Notas:}

${ }^{1}$ Empoderamento se refere à capacidade dos indivíduos ou grupos determinarem seu próprio destino, sendo processo para auxiliá-los a exercer controle dos fatores que afetam suas vidas. Empoderamento possui quatro fatores: econômicos (relacionado ao controle dos ganhos financeiros); psicológicos (autoestima e orgulho local pelas tradições culturais); social (coesão da comunidade); político (consciência cidadã, posse do conhecimento, reflexão sobre relação dominante e dominado) (SCHEYENS, 1999; DI CASTRI, 2004 apud COLE, 2007).

${ }^{2}$ Conceito de convivencialidade sugere relação social em que predomina o interesse de um sujeito pelo outro, possibilitando diálogo intercultural e intercâmbio entre conhecimentos. Na sua essência, a convivencialidade supera a mera relação de negócio, possibilitando resgatar e reconstruir a interconexão entre modos de vida distintos (ILLICH, 1976; SAMPAIO et al., 2011; HENRIQUEZ et al., 2011).

3 Mutirão, palavra do tupi "moti-rõ" - reunião para fins de colheita ou construção (ajuda). (Dicionário de Tupi Guarani, disponível em: http:// www.portalsaofrancisco.com.br/alfa/indios-brasileiros/dicionario-tupi-guarani.php. Acesso em 20 set. 2010).

4 Fandango é considerado expressão musical e artística mais representativa da cultura caiçara (CASCUDO, 2001).

5 "Sendo assim, a criação do Parque não pode ser usada como justificativa para a estagnação econômica das comunidades existentes" (VIVEKANANDA, 2001, p. 105).

6 "'[Nas roças] era muito sofrimento sem lucro. Depois, veio o meio ambiente, aí pararam de vez', explicou o casal Sebastião Antônio e Janice" (BAZZO, 2010, p. 126).

${ }^{7}$ Segundo Seixas (2005), informantes-chave são pessoas capazes de informar sobre um tópico especial, ou de fornecer pontos de vista particulares. As identidades dos informantes-chave foram ocultadas, evitando-se prováveis situações constrangedoras aos depoentes. 
8 Engodo é técnica de pesca que utiliza barro vermelho com peixe cozido que, misturados, formava um pirão grosso, o qual era jogado no mar e, quando os camarões vinham comer, jogava-se a rede (tarrafa).

Gabriel Chagas Teodózio Prudêncio Coutinho: Universidade Federal do Paraná, Curitiba, PR, Brasil.

Email: gabrielctpcoutinho@hotmail.com

Link para o currículo Lattes: http://lattes.cnpq.br/8368956776087226

Carlos Alberto Cioce Sampaio: Pontifícia Universidade Católica do Paraná, Curitiba, PR, Brasil.

Email: carlos.cioce@gmail.com

Link para o currículo Lattes: http://lattes.cnpq.br/9034603212802471

Lígia de Paula Rodrigues: Universidade Federal do Paraná, Curitiba, PR, Brasil.

Email: Idp.rodrigues@gmail.com

Link para o currículo Lattes: http://lattes.cnpq.br/7155958535697579

Data de submissão: 30 de junho de 2012

Data de recebimento de correções: 16 de julho de 2013

Data do aceite: 20 de setembro de 2013

Avaliado anonimamente 